\title{
Führungsprinzipien kennen und Leadership entwickeln
}

\author{
Aufgrund der positiven Feedbacks erfährt das Führungsseminar «Führungsprinzipien \\ kennen und Leadership entwickeln» 2009/2010 eine Neuauflage.
}

Das Führungsseminar geht praxisbezogen auf die wesentlichen Fragen des Führungsalltags von Oberärztinnen und Oberärzten ein und gibt ihnen die Möglichkeit, wichtige Führungstools kennenzulernen, die eigenen Führungskompetenzen zu überdenken und diese strukturiert weiterzuentwickeln.

Das Seminar besteht aus vier Modulen, die thematisch aufeinander abgestimmt sind und eine konzeptuelle Einheit bilden. Darin enthalten sind Aspekte

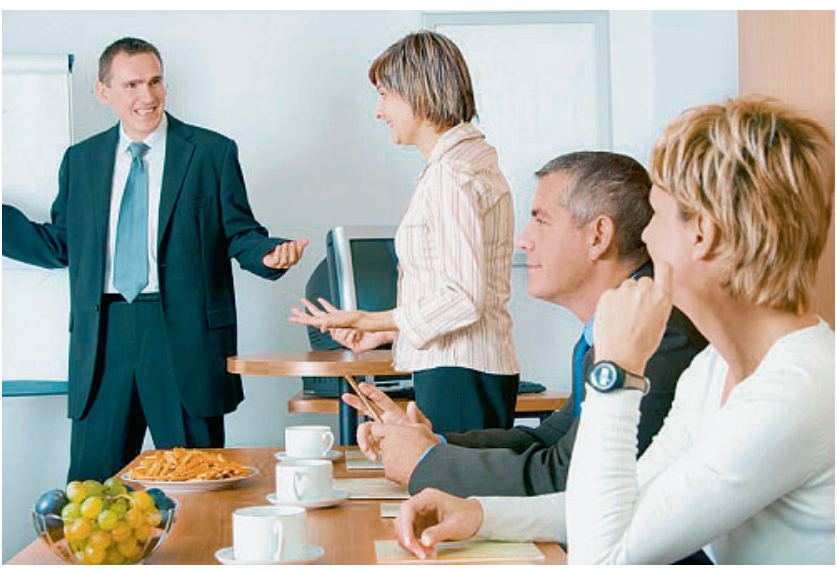

des Führungsverständnisses, der Teamführung und Teamentwicklung, der Kommunikation, des Konfliktmanagements, des Selbstmanagements und des Umgangs mit komplexen Organisationen. Karriereentwicklung und Karriereplanung werden auf Wunsch ebenfalls besprochen. Ausgehend von der Analyse allgemeiner Führungsprinzipien, erwerben die Teilnehmenden konzise Grundlagenkenntnisse und erhalten die Gelegenheit, eigene Ideen im Sinne des Leaderships zu entwickeln. Diese Erkenntnisse und Erfahrungen werden ihnen in ihrer weiteren beruflichen Laufbahn von Nutzen sein.
Das Führungsseminar ist FMH-approved und wird von vielen Fachgesellschaften als persönliche Fortbildung anerkannt. Der Kursbesuch wird offiziell attestiert.

\section{Zielpublikum}

Oberärztinnen und Oberärzte aller medizinischen Fachgebiete.

\section{Dozenten}

Qualifizierte und praxiserfahrene Fachexperten.

\section{Kursdaten}

- 19. und 20. Oktober 2009

- 26. und 27. November 2009

- 4. und 5. März 2010

- 26. und 27. April 2010

\section{Kursort}

Kongress- und Kursaal Bern AG, Bern

\section{Kurskosten}

8 Kurstage inklusive Mittagessen, Getränke, Pausenverpflegung, Infrastruktur und Kursunterlagen: Fr. 4900.-.

\section{Anmeldung}

Bis 15. September 2009.

\author{
Informationen und Kursunterlagen \\ biaggi \& partner, Kurssekretariat \\ Egghölzliweg 4a, Postfach 15, CH-3074 Muri \\ Tel. 0319517234 \\ Fax 0319517210 \\ E-Mail: jean.biaggi@bluewin.ch
}

